\title{
AEROMAGNETIC MAP OF THE SOUTHWESTERN PART OF CUSTER COUNTY, SOUTH DAKOTA
}

By

J. L. Meuschke, R. W. Johnson, and J. R. Kirby

GEOPHYSICAL INVESTIGATIONS

MAP GP-362

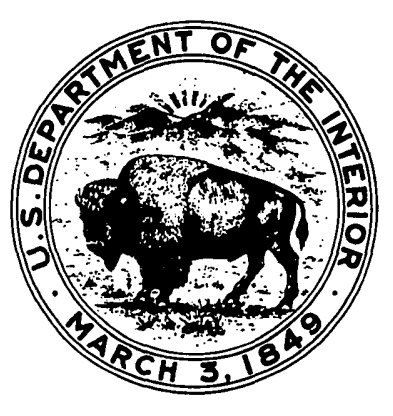

PUBLISHED BY THE U. S. GEOLOGICAL SURVEY 